\title{
Effectiveness of Applying Fatigue Nursing Guidelines on Oncology
}

Patient Health Outcome

\section{Mounira Mohamed Elshahat ${ }^{1}$, Wafaa Ismail Sherief ${ }^{2}$, Eman Saleh Shaheen ${ }^{3}$, Amal \\ Bakr Abo El-Ata ${ }^{4}$}

Nursing science specialist teacher - Alexandria Technical health Institute - ministry of health ${ }^{1}$, Professor of medical surgical Nursing, Faculty of nursing, Mansoura University ${ }^{2}$, Assistant Professor of medical surgical Nursing, Faculty of Nursing, Port Saied University $^{3,4}$

\begin{abstract}
Background: Cancer related fatigue recognizes as one of the most regularly stated and distressing side effects reported by most of cancer patients and significant has long-term effect on the quality of life. Indeed, Fatigue can affect on the patient's life including physical, psychological, social and spiritual aspects. Aim: evaluate the effect of applying fatigue nursing guidelines on oncology patient health outcome. Research design: Quasi experimental design was used in this study. Sample: A convenient sample of 94 cancer patients with a fatigue reported 4 or more on a 0 to 10 numeric screening scale. Setting: the study was conducted in oncology unit at Mansoura University and Port Said General Hospitals. Methods: The study implement the National Comprehensive Cancer Network guidelines for cancer related fatigue, Functional Assessment of Chronic Illness Therapy Fatigue Scale and Fatigue management barriers were measured at baseline, one month, and three months after intervention. Results: Participants experienced significant improvements in fatigue degrees at one-month assessment, and these improvements were continued at three-month assessment. Conclusion: The nursing fatigue guideline based on the National Comprehensive Cancer Network fatigue guideline was effective in reducing fatigue severity.
\end{abstract}

Key words: Fatigue management barriers, Cancer related fatigue, Reducing fatigue guideline. 


\section{INTRODUCTION}

Fatigue is one of the most regularly reported, distressing side effects reported by most of cancer patients and significant has long-term effect on the quality of life and is recognized to be one of the main symptoms of pain. It continues after implementation of the standard treatment course, Also, nearly of cancer patients suffering from fatigue in the terminal stage. National Comprehensive Cancer Network (NCCN) definite the Cancerrelated fatigue (CRF) as a continuous, distressing, subjective sense of emotional, cognitive, and/or physical of tiredness or exhaustion associated with cancer or its treatment that is not related to recent activity and affects with regular functioning. The incidence of CRF in the literature is variable and has been detected to range from $4 \%$ to 91\%, depending on the participants and assessment tools. (Hirai, Kanda, Takagai, \& Hosokawa, 2015; NCCN, 2016).

The causes of cancer-related fatigue is ambiguous, and a variety of mechanisms may interfere with its development. These include impact of cancer and its treatment on physical and psychological impairment beside the pain, nausea and vomiting which are regularly due to the cancer and the cancer treatments. The most common symptoms of cancer-related fatigue include physical fatigue (e.g. inactivity and stress) and mental fatigue (e.g. reduced level of attention, concentration, learning, and short-term memory loss) (Mohandas, Jaganathan, Mani, Ayyar, \& Rohini Thevi, 2017).

Although, there are multiple assessment tools have been developed for fatigue screening, there are no agreements on the best assessment tool. Evaluation and treatment of cancer fatigue according to NCCN is based on four phases: first; screening, second; primary evaluation, third; intervention, and fourth; re-assessment. Screening is done by quantitative or semi-quantitative assessment tools. Diagnosis of CRF excludes reversible treatable with associated factors such as pain, hypothyroidism, emotional distress, electrolyte imbalance, metabolism disturbances, or organ dysfunctions. Primary evaluation includes the patient's history, physical examination and evaluation of current cancer treatment. Then the CRF intervention is planned according to the fatigue assessment and primary evaluation for the patient, subsequent by re-evaluation at regular intervals of current treatment (Banipal, Singh, \& Singh, 2017; Strebkova, Petkova, \& Minev, 2017). 
The treatment of CRF can be divided into pharmacologic and nonpharmacologic management. Medication therapy for fatigue is not always recognized. Although suggestion to use hemopoietic growth factors to treat cancer related fatigue, it cannot use for long time regarding safety matters. However, there is researches suggested that the use of psychostimulants to treat $\mathrm{CRF}$, additional trials are essential to approve these results. Nonpharmacologic interventions emphasis on psychosocial therapy and exercise. psychoeducation, psychotherapy or social support may include as psychosocial interventions (Schroder \& Mackenzie, 2019).

Several barriers which delay the implementation of the NCCN guidelines into practice for the assessment and treating of CRF are like patient, health care provider, and system-related barriers experienced with assessing and managing cancer-related symptoms. Regarding the patient's barriers, cancer patients usually do not discuss their fatigue with the health care providers, fearing that their medical treatment might be negatively affected. fearing that the fatigue mean that the disease is deteriorated. Cancer Patient also may accept that they should live with it because there is nothing that can be done to treat it (Nayak, George, Vidyasagar, Mathew, Shashidhara, \& Kamath, 2015; Chiba, Sasahara, \& Mizuno, 2019).

Oncology nurses accept main duty for fatigue assessment, provide pharmacological and nonpharmacological therapies follow up and assess patient responses to its therapies. NCCN guidelines (2016) using evidence indorse several interventions for patients undergoing cancer treatment. These are generally categorized as: patient/family education, general approaches for fatigue management, nonpharmacological and pharmacological interventions (Berger, Sandra, \& Jacobsen, 2015; Kurtin, \& fuoto, 2019).

\section{Significance of study:}

Cancer related fatigue prevalence rate ranged from $25 \%$ to $99 \%$ and can continue up to five years after completion of treatment. Also, CRF is a potential contributing factor to treatment noncompliance, treatment modifications and early discontinuation of treatment, which in turn might have negative impact on clinical outcomes. Therefore, this study will evaluate the impact of implementing fatigue nursing intervention guidelines on oncology patient health outcome and determine barriers that could affect oncology 
patient response to nursing intervention. This intervention demonstrates modification by translating the fatigue guidelines as developed by the National Comprehensive Cancer Network (NCCN) into clinical practice (NCCN, 2016; Sweegers, et al., 2019).

\section{AIM OF STUDY:}

This study was designed to: evaluate the effect of applying fatigue nursing guidelines on oncology patient health outcome at the clinical oncology and nuclear medicine department at main Mansoura university hospital.

\section{Objectives:}

1. Assess level of oncology patients' fatigue.

2. Adapt nursing care guidelines for fatigue of oncology patients

3. Implemented adapted nursing care guidelines for fatigue of oncology patients

4. Assess effect of applying nursing care guidelines for fatigue on oncology patient's health outcome.

\section{Research hypotheses}

The fatigue nursing intervention guidelines will have a positive effect on oncology patient's health outcome.

\section{SUBJECTS AND METHOD:}

A quasi-experimental research design without control group was applied in the conduction of the current study to evaluate the effect of implementing fatigue nursing intervention guidelines on oncology patient health outcome.

\section{Subjects:}

A convenience sample of 94 adult cancer patients with fatigue who were received care based on fatigue nursing guidelines.

\section{Included criteria:}

- Able to communicate verbally.

- Diagnosis of cancer minimum by one-month before study conduction.

\section{Exclusions criteria:}

- Patients who may experience rapid progression with later-stage disease

- Patients who suffering from fatigue on rating $\leq 4$ on a 0 to 10 numeric screening scale. 


\section{Sample size:}

- The sample size was determined using the following equation (Dobson, 1984):

Since the prevalence and Fatigue among Oncology Patient was 94\% this substituting in the following equation:

$$
\mathrm{Z}^{2}
$$

Sample size $(n)=$-------------- $\quad P(100-P)$

$$
\Delta^{2}
$$

$\mathrm{n}=$ sample size

$\mathrm{p}=$ prevalence of Fatigue among Oncology Patient was 94\%

$\mathrm{Z}=\mathrm{a}$ percentile of the standard normal distribution by $95 \%$ confidence level $=1.96$

$\Delta^{2}=$ the width of the confidence interval $=5.0$

The calculated sample size is 86 patients. Due to the expected non-participating rate (10\%), the final sample size will be 94 patients with fatigue among Oncology Patients.

\section{Data collection tools}

Three tools were used in data collecting as the following:

Tool one: The fatigue Intensity Rating Scale, it's a global rating scale, which validated to assess fatigue in cancer patients developed by Schwartz et al. (2002).

This tool is unidimensional tool consists of 11-item numeric rating scale which measures patients fatigue on a 0 (no fatigue) to 10 (overwhelming fatigue) scale. It was reported by patients to ensure that patients suffering moderate to severe levels of fatigue $(\geq 4)$ to be appropriate for the study.

\section{Tool two: Functional Assessment of Chronic Illness Therapy Fatigue Scale (The}

FACIT-F scale), that developed by Cella (2010) and it consist of 13 items to assess the patient's level of fatigue through their regular daily activities at the previous week. 
Scoring system: This scale is a five-point Likert scale used to assess the of fatigue level with zero indicating very much fatigued and four stands for not at all fatigued, EXCEPT items 7 and 8 which are reversed scored. Score range 0-52. A score of less than 30 indicates severe fatigue.

Tool three: The Fatigue Barriers Scale (FMBQ), that developed by Passik et al. (2002) and it include 28 items. It contains 10 subscales named treatment futility, fear of disease progression, concern of being a good patient, fear of distraction the doctor, lack of concern, fear of stigma, general medication concern, preference of non-medication intervention, fear of jeopardizing cancer treatment, and lack of communication. Each subscale involved 2 items except concern of being a good patient, lack of concern, general medication concern, and preference of non-medication intervention involved 4 items.

Scoring system: A Five-point Likert scale used to assess barriers to fatigue management as: $1=$ strongly agree, $2=$ agree, $3=$ natural, $4=$ disagree and $5=$ strongly disagree.

Patients' personal demographic characteristics as age, gender, occupation, level of education, and marital status will be added to study tools.

\section{Operational design}

The operational design, which was the second phase of the present study, it was included description of the study preparatory phase, the pilot study and the fieldwork.

\section{Preparatory phase:}

During this phase, the researcher reviewed local and international related literature using internet search, textbooks and scientific journals. This helped in increasing acquaintance with the study subject and in the preparation of the data collection tools.

\section{Content validity:}

Once the tools were prepared in their preliminary form, they were presented to a panel of 13 expertise in medical and nursing academic staff. Also, from medical and nursing staff in hospital who provide the direct care for patient with cancer for content 
validation. The tools were then adjusted based upon the recommendations of these experts.

\section{Reliability:}

Cronbach's alpha-coefficient was calculated for Arabic translated tools which were high reliability for all tools as following:

- The Fatigue Intensity Scale which reliability was 0.851 ,

- Functional Assessment of Chronic Illness Therapy (FACIT-F) Fatigue Scale reliability was 0.887

- The Fatigue Barriers Scale (FMBQ) reliability was 0.985

\section{Pilot study:}

A pilot study was carried out before starting the data collection. It applied on (10\%) of study sample (10 patients) with cancer patients with fatigue who meet the study criteria attending at Clinical Oncology and Nuclear Medicine Department at Main Mansoura University Hospital and the main Port Said Hospital. Each patient assessment took from 30 to 45 minutes. According the findings of the pilot study were not included in the main sample since some modifications were done in the tools in the form of rephrasing some items.

\section{Field work: -}

This study was achieved through four phases, namely assessment, planning, implementation and evaluation.

\section{Assessment phase:}

This phase involved preparation of the tools to assess cancer patient fatigue intensity and patient-reported barriers to fatigue management. After obtaining the patient consent, individual interviews were done with the cancer patients with fatigue in the hospitals at the time of visiting according to hospital policy. Assessment of each patients took approximately 30-45 minutes. The data collected was used as base-line data that served in implementing the fatigue nursing intervention guidelines and later evaluation of the guidelines effectiveness after one- and three-months assessment. 


\section{Planning phase:}

The researcher demonstrates modification by translating the fatigue guidelines as developed by the National Comprehensive Cancer Network (NCCN) guidelines into clinical practice. The guidelines overall purpose was to improve patient outcome about fatigue.

\section{Implementation Phase:}

Implementation of the guideline was carried out at inpatient and outpatient chemotherapy clinics in the study setting, was done through individual teaching. Each patient received four educational sessions. At each session, information about fatigue assessment and fatigue management, was provided each session range from 30-45 minute. At beginning of the first session of the health - teaching module the patients were oriented about the guidelines' objectives, contents, purpose and its impact. The intervention was implemented four days per week during a period from August 2018 to August 2019.

The researcher develops nursing intervention according to NCCN guidelines after assessing the participants individually for fatigue. the intervention may be as following:

- Encourage the patient to express his feeling as part of decrease his stress.

- Give health education about appropriate nutrition and how dealing with nausea and vomiting induced by analgesics also the alternative nutrition for anemia as main cause of fatigue (as eat high-calorie, nutrient-rich diet, with adequate fluid intake and use of supplements and frequent or smaller meals spaced throughout the day).

- Allow the patient to take rest period and assist him during daily activity as fatigue make daily activity difficult to complete and put him in risk of injury.

Following the education and beginning at one-month post-accrual, all patients were retained and supported through bi-weekly phone contacts.

Following the education and beginning at one-month after baseline assessment, all patients were followed up and supported each two weeks by phone contacts. 


\section{Evaluation Phase:}

After the baseline assessment and the guideline implementation, outcome measures were repeated later at one- and three-months post implementation to evaluate the effect of the guideline on the patient outcome.

\section{Administrative design}

Official letters from the faculty of nursing, Port- Said University, were addressed to the General Directors of the Oncology institute, and permission was obtained to conduct the study after explanation of the study objectives.

\section{Ethical Considerations:}

The research and research committee in the Faculty of Nursing approved the study protocol. The aim and procedures of the study was explained clearly and simply to every patient invited to participate in the study to obtain her/his consent. The researcher assured the patient that the information will be used only for the purpose of the study and will be strictly confidential. They were informed about their right to refuse to participate or withdraw at any time without giving reason and with no consequences on the care.

\section{Statistical design:}

Data entry and statistical analysis were done using SPSS version 20.0 statistical software packages. Data were presented using descriptive statistics in the form of number, percentages, arithmetic means \&standard division for quantitative variables.

\section{RESULT:}

Table (1): shows that about third of studied patients (34\%) in age group from 51 to 56 years old. Female were $(55.3 \%)$ of the participants, $(28.7 \%)$ were not educated, most of the participants $(71.3 \%)$ were married, and house wife were $(42.6 \%)$ from them.

Table (2): showed that the fatigue severity at baseline assessment was sever by mean of \pm SD $7.77 \pm 1.45$ then it decreased at one-month after fatigue nursing care guidelines to $4.76 \pm 1.95$ to be moderate while. it raised slightly again after the three-month of the nursing care guidelines implementation but still moderate level fatigue with means of $6.03 \pm 1.73$. There were highly significant differences between fatigue intensity at baseline 
assessment and both at one month and at three months from applying the fatigue nursing care guidelines with $\mathrm{P}$ - value of $<0.001$

Table (3): showed that the total mean \pm SD score of FACT-F at the baseline assessment was $17.82 \pm 6.61$, which the total mean \pm SD score reached to $26.56 \pm 6.15$ one month after nursing care guidelines implementation and $23.02 \pm 6.77$ after three months of guidelines implementation. Moreover, the study results found highly significant differences between baseline fatigue level and after one-month, three months of implementing fatigue nursing care guidelines regarding all items.

Table (4): showed significant relationship between FACT-F score and patients age and gender in baseline assessment and after three months after applying nursing care guidelines However, the current study results revealed a significant relationship only between FACT-F sore and level of education three months after applying the nursing care guidelines.

Table (5): showed that all barriers subscales means were lower at one-month assessment than the base line assessment, then rises little bite at the three-months assessment phase but still less than the base line . Also, the main of all the barriers aspect at the one-month assessment phase was less than at the baseline assessment phase. Also, the tabled showed highly significant between all aspects in all the assessment phase except according the fear of jeopardizing cancer treatment aspect there is no significant between baseline assessment and at three months assessment.

Table (6): showed no significant relationship between the fatigue management barriers and the patients' personal characteristics while marital status associated significantly with the total fatigue management barriers in the baseline assessment phase. 
Table (1): Distribution of personnel demographic characteristics of the studied patients $(n=94)$.

\begin{tabular}{|c|c|c|}
\hline Variable & No & $\%$ \\
\hline \multicolumn{3}{|l|}{ Age } \\
\hline 20-35 years & 23 & 24.5 \\
\hline $36-50$ years & 22 & 23.4 \\
\hline $51-65$ years in years & 32 & 34 \\
\hline$>65$ years & 17 & 18.1 \\
\hline \multicolumn{3}{|l|}{ Gender } \\
\hline Male & 42 & 44.7 \\
\hline Female & 52 & 55.3 \\
\hline \multicolumn{3}{|l|}{ Level of education } \\
\hline Not educated & 27 & 28.7 \\
\hline Read and write & 10 & 10.6 \\
\hline Essential education & 8 & 8.5 \\
\hline Secondary education & 26 & 27.7 \\
\hline University graduate & 21 & 22.4 \\
\hline Post graduate study & 2 & 2.1 \\
\hline \multicolumn{3}{|l|}{ Marital status } \\
\hline Single & 16 & 17 \\
\hline Divorced & 3 & 3.2 \\
\hline Married & 67 & 71.3 \\
\hline Widow/widower & 8 & 8.5 \\
\hline \multicolumn{3}{|l|}{ Occupation } \\
\hline Officer work & 21 & 22.3 \\
\hline Manual work & 20 & 21.3 \\
\hline House wife & 40 & 42.6 \\
\hline not working & 13 & 13.8 \\
\hline
\end{tabular}


Table (2): Fatigue intensity scale among the studied subjects at different assessment phases.

\begin{tabular}{|c|c|c|c|c|c|c|c|c|}
\hline \multirow[t]{2}{*}{ Scale } & \multicolumn{2}{|c|}{$\begin{array}{c}\text { baseline and after } 1 \\
\text { month }\end{array}$} & \multirow{2}{*}{$\begin{array}{c}\text { Paired } \\
\text { t test } \\
(1)\end{array}$} & \multirow[t]{2}{*}{ P value } & \multicolumn{2}{|c|}{$\begin{array}{c}\text { baseline and after } 3 \\
\text { months }\end{array}$} & \multirow[t]{2}{*}{$\begin{array}{l}\text { Paired t } \\
\text { test (2) }\end{array}$} & \multirow[t]{2}{*}{$\begin{array}{c}\mathbf{P} \\
\text { value }\end{array}$} \\
\hline & Mean \pm SD & Mean \pm SD & & & Mean \pm SD & Mean \pm SD & & \\
\hline $\begin{array}{l}\text { Fatigue } \\
\text { intensity scale }\end{array}$ & $7.77 \pm 1.45$ & $4.76 \pm 1.95$ & 22.97 & $<0.001 * *$ & $7.77 \pm 1.45$ & $6.03 \pm 1.73$ & 19.01 & $\begin{array}{c}<0.001^{*} \\
*\end{array}$ \\
\hline
\end{tabular}

Table (3): distribution of mean score of the FACIT-F subscale among the studied subjects at different assessment phases.

\begin{tabular}{|c|c|c|c|c|c|c|c|c|}
\hline \multirow[t]{2}{*}{ Variable } & \multicolumn{2}{|c|}{$\begin{array}{c}\text { baseline and after } 1 \\
\text { month }\end{array}$} & \multirow{2}{*}{$\begin{array}{l}\text { Paired t } \\
\text { test (1) }\end{array}$} & \multirow[t]{2}{*}{ P value } & \multicolumn{2}{|c|}{$\begin{array}{c}\text { baseline and after } 3 \\
\text { months }\end{array}$} & \multirow{2}{*}{$\begin{array}{c}\text { Paired } \\
\text { t test } \\
\text { (2) }\end{array}$} & \multirow[t]{2}{*}{ P value } \\
\hline & Mean \pm SD & Mean \pm SD & & & Mean \pm SD & Mean \pm SD & & \\
\hline I feel fatigued & $0.98 \pm .81$ & $2.28 \pm 0.88$ & 12.861 & $<0.001 * *$ & $0.98 \pm .81$ & $1.94 \pm 0.98$ & 9.668 & $<0.001 * *$ \\
\hline I feel weak all over & $0.91 \pm .80$ & $2.16 \pm 0.80$ & 14.981 & $<0.001 * *$ & $0.91 \pm .80$ & $1.85 \pm 0.95$ & 11.207 & $<0.001 * *$ \\
\hline $\begin{array}{l}\text { I feel listless ("washed } \\
\text { out") }\end{array}$ & $0.94 \pm .83$ & $2.13 \pm .78$ & 14.192 & $<0.001 * *$ & $0.94 \pm .83$ & $1.7 \pm .91$ & 11.642 & $<0.001 * *$ \\
\hline I feel tired & $0.98 \pm .85$ & $2.22 \pm 0.88$ & 13.088 & $<0.001 * *$ & $0.98 \pm .85$ & $1.7 \pm 0.94$ & 10.309 & $<0.001 * *$ \\
\hline $\begin{array}{l}\text { I have trouble starting } \\
\text { things because I am tired }\end{array}$ & $0.95 \pm .86$ & $2.09 \pm 0.87$ & 12.675 & $<0.001 * *$ & $0.95 \pm .86$ & $1.73 \pm .95$ & 11.524 & $<0.001 * *$ \\
\hline $\begin{array}{l}\text { I have trouble finishing } \\
\text { things because I am tired }\end{array}$ & $0.97 \pm .85$ & $2.06 \pm .84$ & 12.291 & $<0.001 * *$ & $0.97 \pm .85$ & $1.67 \pm 0.91$ & 8.833 & $<0.001 * *$ \\
\hline I have energy & $3.31 \pm 0.86$ & $1.43 \pm 0.81$ & -16.044 & $<0.001 * *$ & $3.31 \pm 0.86$ & $1.7 \pm 1.02$ & -14.486 & $<0.001 * *$ \\
\hline $\begin{array}{l}\text { I am able to do my usual } \\
\text { activities }\end{array}$ & $3.29 \pm 0.89$ & $1.43 \pm 0.90$ & -16.174 & $<0.001 * *$ & $3.29 \pm 0.89$ & $1.66 \pm 1.01$ & -16.155 & $<0.001 * *$ \\
\hline $\begin{array}{l}\text { I need to sleep during the } \\
\text { day }\end{array}$ & $1.01 \pm 0.81$ & $2.00 \pm 0.92$ & 10.429 & $<0.001 * *$ & $1.01 \pm 0.81$ & $1.75 \pm 0.95$ & 8.874 & $<0.001 * *$ \\
\hline I am too tired to eat & $1.37 \pm .93$ & $2.24 \pm 0.94$ & 8.767 & $<0.001 * *$ & $1.37 \pm .93$ & $1.88 \pm 1.01$ & 6.004 & $<0.001 * *$ \\
\hline $\begin{array}{l}\text { I need help doing my } \\
\text { usual activities }\end{array}$ & $1.12 \pm .82$ & $2.23 \pm 0.86$ & 10.627 & $<0.001 * *$ & $1.12 \pm .82$ & $1.87 \pm .96$ & 9.040 & $<0.001 * *$ \\
\hline $\begin{array}{l}\text { I am frustrated by being } \\
\text { too tired to do the things I } \\
\text { want to do }\end{array}$ & $0.97 \pm .88$ & $2.12 \pm 0.88$ & 11.352 & $<0.001 * *$ & $0.97 \pm .88$ & $1.8 \pm 0.96$ & 8.829 & $<0.001 * *$ \\
\hline $\begin{array}{l}\text { I have to limit my social } \\
\text { activity because I am tired }\end{array}$ & $1.02 \pm 0.86$ & $2.17 \pm 0.93$ & 10.246 & $<0.001 * *$ & $1.02 \pm 0.86$ & $1.77 \pm 0.93$ & 8.892 & $<0.001 * *$ \\
\hline Total & $17.82 \pm 6.61$ & $26.56 \pm 6.15$ & 14.50 & $<0.001 * *$ & $17.82 \pm 6.61$ & $23.02 \pm 6.77$ & 11.42 & $<0.001 * *$ \\
\hline
\end{tabular}


Table (4): Correlation between personal's demographics characteristics and the FACT-F at the three assessment phases among the studied subjects

\begin{tabular}{|c|c|c|c|}
\hline \multirow[t]{3}{*}{ Variable } & \multicolumn{3}{|c|}{ FACIT-F subscale score } \\
\hline & Baseline & After 1 month & After 3 months \\
\hline & Mean \pm SD & Mean \pm SD & Mean \pm SD \\
\hline \multicolumn{4}{|l|}{ Age } \\
\hline $20-35$ years & $18.7 \pm 6.35$ & $26.13 \pm 5.73$ & $23.39 \pm 6.24$ \\
\hline 36-50 years & $16.32 \pm 6.40$ & $24.82 \pm 7.18$ & $20.5 \pm 8.09$ \\
\hline $51-65$ years in years & $19.69 \pm 7.06$ & $28.5 \pm 5.31$ & $25.28 \pm 6.29$ \\
\hline$>65$ years & $14.5 \pm 4.93$ & $25.62 \pm 6.33$ & $21.37 \pm 5.21$ \\
\hline F test p value & $2.87 \quad<0.05^{*}$ & $1.85>0.05$ & $2.68<0.05^{*}$ \\
\hline \multicolumn{4}{|l|}{ Gender } \\
\hline Male & $18.48 \pm 6.58$ & $26.43 \pm 6.10$ & $23.69 \pm 6.61$ \\
\hline Female & $17.16 \pm 6.64$ & $26.65 \pm 6.26$ & $22.45 \pm 6.91$ \\
\hline Independent $\mathrm{t}$ test & $0.959<0.05 *$ & $>0.05$ & $0.882<0.05 *$ \\
\hline \multicolumn{4}{|l|}{ Level of education } \\
\hline Illiterate & $15.93 \pm 6.79$ & $26.19 \pm 6.77$ & $22.22 \pm 6.85$ \\
\hline Read and write & $15.9 \pm 4.98$ & $26.4 \pm 5.48$ & $21.6 \pm 7.60$ \\
\hline Basic education & $23.37 \pm 8.38$ & $29.00 \pm 6.00$ & $27.37 \pm 9.26$ \\
\hline Secondary education & $17.85 \pm 5.81$ & $26.27 \pm 5.87$ & $23.08 \pm 5.53$ \\
\hline Bachelor & $18.68 \pm 6.41$ & $26.5 \pm 6.38$ & $22.95 \pm 6.62$ \\
\hline p value & $>0.05$ & $>0.05$ & $<0.05 *$ \\
\hline \multicolumn{4}{|l|}{ Marital status } \\
\hline Single & $17.94 \pm 5.94$ & $26.56 \pm 6.28$ & $23.25 \pm 5.77$ \\
\hline Divorced & $16.5 \pm .70711$ & $12.5 \pm 13.44$ & $16.5 \pm 3.54$ \\
\hline Married & $18.24 \pm 7.03$ & $26.82 \pm 5.95$ & $23.34 \pm 7.24$ \\
\hline Widow/widower & $13.62 \pm 3.16$ & $25.5 \pm 6.63$ & $21.73 \pm 4.34$ \\
\hline p value & $>0.05$ & $>0.05$ & 0.829 \\
\hline Occupation & & & \\
\hline Officer work & $18.9 \pm 6.50$ & $28.00 \pm 5.74$ & $24.29 \pm 6.53$ \\
\hline Manual work & $20.4 \pm 6.10$ & $27.7 \pm 5.01$ & $24.55 \pm 7.29$ \\
\hline Housewife & $16.49 \pm 6.91$ & $26.13 \pm 6.61$ & $21.92 \pm 7.15$ \\
\hline not working & $15.62 \pm 5.49$ & $23.7 \pm 6.47$ & $21.85 \pm 4.69$ \\
\hline p value & $>0.05$ & $>0.05$ & $>0.05$ \\
\hline
\end{tabular}


Table (5): Distribution of mean score of fatigue management barriers questionnaire

\begin{tabular}{|c|c|c|c|c|c|c|c|c|}
\hline & $\begin{array}{r}\text { baseline a } \\
\text { mo }\end{array}$ & $\begin{array}{l}\text { nd after } 1 \\
\text { nth }\end{array}$ & $\begin{array}{l}\text { Paired t } \\
\text { test }(1)\end{array}$ & $P$ value & $\begin{array}{r}\text { baseline a } \\
\text { mo }\end{array}$ & $\begin{array}{l}\text { nd after } 3 \\
\text { ths }\end{array}$ & $\begin{array}{l}\text { Paired t } \\
\text { test (2) }\end{array}$ & $P$ value \\
\hline & Mean \pm SD & Mean \pm SD & & & Mean \pm SD & Mean \pm SD & & \\
\hline $\begin{array}{l}\text { Fear of } \\
\text { Jeopardizing } \\
\text { cancer treatment }\end{array}$ & $3.20 \pm 0.97$ & $2.23 \pm 0.92$ & 22.453 & $<0.001 * *$ & $3.20 \pm 0.97$ & $2.87 \pm 0.91$ & 1.440 & $>.05$ \\
\hline Lack of concern & $3.10 \pm 0.99$ & $2.18 \pm 1.07$ & 10.449 & $<0.001 * *$ & $3.10 \pm 0.99$ & $2.62 \pm 0.97$ & 5.505 & $<0.001 * *$ \\
\hline $\begin{array}{l}\text { Non medication } \\
\text { intervention }\end{array}$ & $3.01 \pm 1.00$ & $2.23 \pm 1.05$ & 15.897 & $<0.001 * *$ & $3.01 \pm 1.00$ & $2.64 \pm 0.93$ & 13.325 & $<0.001 * *$ \\
\hline $\begin{array}{l}\text { Fear of disease } \\
\text { progression }\end{array}$ & $3.07 \pm 1.13$ & $2.22 \pm 0.99$ & 14.848 & $<0.001 * *$ & $3.07 \pm 1.13$ & $2.65 \pm 0.92$ & 5.723 & $<0.001 * *$ \\
\hline $\begin{array}{l}\text { Treatment } \\
\text { futility }\end{array}$ & $3.06 \pm 1.02$ & $2.21 \pm 1.06$ & 15.228 & $<0.001 * *$ & $3.06 \pm 1.02$ & $2.64 \pm 0.94$ & 6.919 & $<0.001 * *$ \\
\hline $\begin{array}{l}\text { General } \\
\text { medication } \\
\text { concern }\end{array}$ & $3.13 \pm 1.02$ & $2.19 \pm 1.07$ & 22.361 & $<0.001 * *$ & $3.13 \pm 1.02$ & $2.63 \pm 0.94$ & 10.943 & $<0.001 * *$ \\
\hline Fear of stigma & $3.10 \pm 1.01$ & $2.20 \pm 2.15$ & 5.703 & $<0.001 * *$ & $3.10 \pm 1.01$ & $2.64 \pm 0.99$ & 27.507 & $<0.001 * *$ \\
\hline Good patient & $3.25 \pm 0.99$ & $2.22 \pm 1.10$ & 12.041 & $<0.001 * *$ & $3.25 \pm 0.99$ & $2.69 \pm 1.01$ & 6.235 & $<0.001 * *$ \\
\hline Communication & $2.99 \pm 0.98$ & $2.19 \pm 1.20$ & 10.720 & $<0.001 * *$ & $2.99 \pm 0.98$ & $2.60 \pm 0.98$ & 5.893 & $<0.001 * *$ \\
\hline $\begin{array}{l}\text { Fear of } \\
\text { distracting } \\
\text { doctor }\end{array}$ & $3.15 \pm 1.00$ & $2.17 \pm 0.99$ & 25.769 & $<0.001 * *$ & $3.15 \pm 1.00$ & $2.66 \pm 0.92$ & 15.455 & $<0.001 * *$ \\
\hline
\end{tabular}

subscales at different assessment phases among the studied subjects. 
Table (6): correlation between personal's characteristics and fatigue management barriers among the studied subjects

\begin{tabular}{|c|c|c|c|}
\hline \multirow[t]{3}{*}{ Variable } & \multicolumn{3}{|c|}{ Total fatigue management barriers score } \\
\hline & Baseline & After 1 month & After 3 months \\
\hline & Mean \pm SD & Mean \pm SD & Mean \pm SD \\
\hline \multicolumn{4}{|l|}{ Age } \\
\hline $20-35$ years & $80.91 \pm 18.96$ & $60.17 \pm 20.96$ & $71.65 \pm 20.66$ \\
\hline $36-50$ years & $89.55 \pm 24.81$ & $66.41 \pm 25.70$ & $78.82 \pm 24.89$ \\
\hline $51-65$ years in years & $87.38 \pm 19.79$ & $58.38 \pm 20.62$ & $72.47 \pm 19.38$ \\
\hline$>65$ years & $94.06 \pm 18.22$ & $63.81 \pm 20.81$ & $76.50 \pm 17.40$ \\
\hline p value & $--->0.05$ & $--->0.05$ & $--->0.05$ \\
\hline \multicolumn{4}{|l|}{ Gender } \\
\hline Male & $85.55 \pm 21.03$ & $59.76 \pm 20.96$ & $73.17 \pm 20.83$ \\
\hline Female & $89.00 \pm 20.65$ & $63.22 \pm 22.75$ & $75.53 \pm 20.71$ \\
\hline adependent $t$ test- $p$ value & $--->0.05$ & $--->0.05$ & $--->0.05$ \\
\hline \multicolumn{4}{|l|}{ Level of education } \\
\hline Illiterate & $90.81 \pm 21.13$ & $62.89 \pm 22.47$ & $74.89 \pm 20.15$ \\
\hline Read and write & $95.10 \pm 22.40$ & $65.00 \pm 22.13$ & $78.40 \pm 22.12$ \\
\hline Basic education & $81.12 \pm 26.76$ & $64.88 \pm 31.16$ & $74.38 \pm 27.56$ \\
\hline Secondary education & $83.96 \pm 19.72$ & $61.62 \pm 20.99$ & $75.19 \pm 21.33$ \\
\hline Bachelor & $86.23 \pm 18.67$ & $57.50 \pm 19.78$ & $71.32 \pm 18.65$ \\
\hline p value & $--->0.05$ & $-->0.05$ & $-->0.05$ \\
\hline Marital status & & & \\
\hline Single & $66.75 \pm 11.31$ & $53.06 \pm 9.61$ & $63.69 \pm 9.65$ \\
\hline Divorced & $84.00 \pm 14.14$ & $58.00 \pm 4.24$ & $68.00 \pm 7.07$ \\
\hline Married & $88.69 \pm 22.53$ & $62.96 \pm 23.78$ & $76.54 \pm 22.37$ \\
\hline Widow/widower & $99.25 \pm 12.26$ & $68.88 \pm 22.98$ & $80.25 \pm 18.55$ \\
\hline p value & $---<0.05 *$ & $--->0.05$ & $--->0.05$ \\
\hline Occupation & & & \\
\hline Officer work & $88.71 \pm 20.28$ & $62.05 \pm 22.39$ & $77.62 \pm 22.50$ \\
\hline Manual work & $79.85 \pm 19.76$ & $55.05 \pm 17.22$ & $66.05 \pm 16.06$ \\
\hline House wife & $91.10 \pm 21.69$ & $65.18 \pm 24.35$ & $77.6667 \pm 22.26$ \\
\hline not working & $86.08 \pm 19.32$ & $60.62 \pm 19.61$ & $72.69 \pm 16.95$ \\
\hline p value & $--->0.05$ & $--->0.05$ & $--->0.05$ \\
\hline
\end{tabular}




\section{DISCUSSION:}

Cancer-related fatigue significantly impaired the daily life activities and quality of life for a large portion of cancer patients and may continue for years after cancer treatment. NCCN Guidelines list the principles of management and recognize the variety of complex choices challenged the management of cancer related fatigue. (NCCN, 2016; LaVoy, Fagundes, \& Dantzer, 2016). So, the aim of this study was to evaluate the effect of implementing fatigue nursing intervention guidelines on oncology patient health outcome. Current study offers validation of the NCCN guidelines for adult cancer fatigue management.

Concerning fatigue intensity scale, data revealed that the mean of its decreased at one-month assessment than baseline assessment and elevated again at three-months assessment, even its mean at three-months assessment still less than the baseline assessment mean. These findings matching with Yennurajalingam et al (2011) who suggest that that associated symptoms such as pain, dyspnea, depression, or nausea must be assessed and managed in all patients expressing fatigue because such multidimensional management rises the possibility of fatigue improvement. Although, the current study not matching with the study conduct on France build based on NCCN guidelines by Bourmaud et al (2017) who reported that no impact of the program was highlighted on the patient's outcomes.

Cancer-related fatigue is the most common symptom reported by cancer patients, and it may persist for years after treatment (Oertle, Burrell, \& Pirollo, 2016). Functional assessment of chronic illness therapy scale reflects on the level of fatigue in the three study assessment phases and the effect of the applied nursing guideline on fatigue. This study found that the level of fatigue decreased at the one-month assessment and at the three-months assessment than before applying the guidelines with highly significant relationship between the pre-applying guidelines assessment and at the one-months assessment and between the pre-applying guidelines assessment and at the three-months assessment. It is consistent with study conducted on china by Tian et al, (2017) who reported that during the pre-implementation of evidence-based practice project, the most severe cancer related fatigue scores during and after implementation was moderate the evidence based practice project cancer related fatigue score lower to be moderate also but 
less than before This finding is corresponding with decrease the fatigue intensity which reflect on the other fatigue assessment items.

This results goes in the same line with the study done in Indonesia by Werdani (2018) who mentioned that most of the cancer patients had severe fatigue and the researcher defined severe fatigue as the fatigue felt by the patients for the last 24 hours that disrupts their activity, worsens their mood, and prevents interaction with others, so the enjoyment of life is interrupted. Also, it may be attributed to that the etiology of cancer related fatigue is complex and multidimensional, including several actual aspects. These involve the cancer, the side effects of cancer treatments, comorbid and psychological conditions (Dietrich \& Parsons, 2018).

A significant relationship was found between age and level of fatigue, the study subjects who age > 65years suffered from fatigue significantly higher than the younger subjects, this finding is congruent with Tabrizi and Alizadeh (2017) who reported that there was a significantly positive association between age and fatigue score. also corresponding with Breda and Watts (2017) who reported that the older people who interpretation functional deteriorations as a portion of the aging process are less expected to ask care, to involve in protective behaviors such as exercise and healthy food, or to follow the medical treatments.

The present study clarified that there was a significant relationship between the level of fatigue and gender. This finding is not corresponding with Bevilacqua et al, (2018) who stated that Women reported significantly higher levels of fatigue compared to male survivors. Moreover, significant relationship was found at three months assessment phase between level of education and level of fatigue as illiterate subjects had high level of fatigue. It's corresponding with who Junghaenel, Christodoulou, \& Stone (2011) explored the relation of fatigue to education and found that higher academic degree were associated with less fatigue. This may be attributed to literate subjects responding to the NCCN guidance and the researcher guidance.

The fatigue management barriers questionnaire showed accepted inconsistency among expertise and was exposed to be a reliable tool which could be recognize barriers to suitable identification and management of fatigue. There were significant at onemonth assessment and at three months assessment phases of the nursing guideline on all fatigue management barriers subscales, and on the Total score. as The study found that 
the fatigue barriers decreased at one- month assessment and at three months assessment phases with highly significant between the baseline and at one-month assessment and between baseline and at the three months assessment which indicate that the nursing guideline scientifically effect on the fatigue management barriers and it corresponding with Borneman et al. (2013) who found that immediate and continued impacts significant were exposed on the fatigue barriers scale regarding the intervention group. Insistent barriers to fatigue management were significantly improved.

Want to be good patient and fear of jeopardizing cancer treatment were the highest stated barrier to fatigue management in this study, while fear of jeopardizing cancer treatment was the tenth ordered barrier to reporting fatigue management according Shun, Lai, \& Hsiao (2009) in the study carried in Taiwan. on the other hand, the study confirmed that the highest reported barrier to fatigue communication was fear of distracting the doctor.

The current study found that there is no any statistically significant relation between fatigue management barriers and patient characteristics except according the marital status as the widow/ widower subjects reported highly barriers score toward fatigue management. This is contrast with Sun et al., (2012) who mentioned that fatigue management barriers is highly significant with socioeconomic characteristics as age, sex, income, level of education and marital status. Although the study subjects consisted of patients with various backgrounds, the study plan was to enroll patients who had moderate to severe fatigue. Therefore, the study findings may not be stated for patients who are less symptomatic.

\section{CONCLUSION:}

Fatigue nursing care guidelines was effective in reducing severity of fatigue among oncology patient. Also, decreasing patient barriers to fatigue management. These guidelines demonstrates patient fatigue improvement by translating the National Comprehensive Cancer Network fatigue guidelines into practice.

\section{RECOMMENDATIONS:}

Patient should encourage to use daily diary for assessing the severity of fatigue as it helps the health care providers to determine effective management. Informing cancer patients that fatigue can be managed, just need to set realistic outcome. Also, health care 
provider should ensure that the patients and their care giver receive appropriate educational materials for symptoms management and reducing the barriers. Written booklet and learning session should provide to the patient to increase their knowledge about fatigue and fatigue management. Repeated this research on large sample to ensure generalizability of the study.

\section{REFERENCES:}

Banipal, R. P. S., Singh, H., \& Singh, B. (2017). Assessment of cancer-related fatigue among cancer patients receiving various therapies: A cross-sectional observational study. Indian journal of palliative care, 23(2), 207.

Berger, A. M., Mitchell, S. A., Jacobsen, P. B., \& Pirl, W. F. (2015). Screening, evaluation, and management of cancer-related fatigue: Ready for implementation to practice?. CA: a cancer journal for clinicians, 65(3), 190-211

Bevilacqua, L. A., Dulak, D., Schofield, E., Starr, T. D., Nelson, C. J., Roth, A. J., ... \& Alici, Y. (2018). Prevalence and predictors of depression, pain, and fatigue in older-versus younger-adult cancer survivors. Psycho-oncology, 27(3), 900-907.

Borneman, T. (2013). Assessment and management of cancer-related fatigue. Journal of Hospice \& Palliative Nursing, 15(2), 77-86.

Bourmaud, A., Anota, A., Moncharmont, C., Tinquaut, F., Oriol, M., Trillet-Lenoir, V., ... \& Pérol, D. (2017). Cancer-related fatigue management: evaluation of a patient education program with a large-scale randomised controlled trial, the PEPs fatigue study. British journal of cancer, 116(7), 849.

Breda, A. I., \& Watts, A. S. (2017). Expectations regarding aging, physical activity, and physical function in older adults. Gerontology and Geriatric Medicine, 3, 2333721417702350 .

Cella, D.(2010) . Functional Assessment of Chronic Illness Therapy (FACIT) Fatigue Scale (The FACIT-F subscale). [Accessed February 20, 2016]. Available at from www. FACIT.org 
Chiba, I., Sasahara, T., \& Mizuno, M. (2019). Factors in Cancer-Related Fatigue SelfManagement Behaviors of Outpatients Undergoing Chemotherapy. Asia-Pacific Journal of Oncology Nursing, 6(3), 209.

Dietrich, J., \& Parsons, M. W. (2018). Cognitive dysfunction, mood disorders, and fatigue as complications of cancer. In Cancer Neurology in Clinical Practice (pp. 203-219). Springer, Cham.

Dobson, A. (1984). Calculating sample size. Trans Menziez Foundation, 7,75-79.

Hirai, K., Kanda, K., Takagai, J., \& Hosokawa, M. (2015). Development of the Hirai Cancer Fatigue Scale: testing its reliability and validity. European Journal of Oncology Nursing, 19(4), 427-432.

Junghaenel, D. U., Christodoulou, C., Lai, J. S., \& Stone, A. A. (2011). Demographic correlates of fatigue in the US general population: results from the patient-reported outcomes measurement information system (PROMIS) initiative. Journal of psychosomatic research, 71(3), 117-123.

Kurtin, S., \& fuoto, A. (2019). Pain Management in the Cancer Survivor. Seminar in oncology nursing, Seminars in Oncology Nursing, 35(3), 284-290.

LaVoy, E. C., Fagundes, C. P., \& Dantzer, R. (2016). Exercise, inflammation, and fatigue in cancer survivors. Exercise immunology review, 22, 82.

Mohandas, H., Jaganathan, S. K., Mani, M. P., Ayyar, M., \& Thevi, G. R. (2017). Cancer-related fatigue treatment: An overview. Journal of cancer research and therapeutics, 13(6), 916.

National Comprehensive Cancer Network, 2016. NCCN Clinical Practice Guidelines in Oncology: Cancer-related Fatigue.

Nayak, M. G., George, A., Vidyasagar, M. S., Mathew, S., Nayak, S., Nayak, B. S., ... Kamath, A. (2015). Symptoms experienced by cancer patients and barriers to 
symptom management. Indian journal of palliative care, 21(3), 349-354. doi:10.4103/0973-1075.164893

Oertle, S., Burrell, S., \& Pirollo, M. (2016). Evaluating the Effects of a PhysicianReferred Exercise Program on Cancer-Related Fatigue and Quality of Life Among Early Cancer Survivors. Journal of Oncology Navigation \& Survivorship, 7(2).

Passik, S. D., Kirsh, K. L., Donaghy, K., Holtsclaw, E., Theobald, D., Cella, D., \& Breitbart, W. (2002). Patient-related barriers to fatigue communication: initial validation of the fatigue management barriers questionnaire. Journal of pain and symptom management, 24(5), 481-493.

Schroder, J., \& Mackenzie, L. (2019). The impact of non-pharmacological cancer-related fatigue interventions on activity performance and participation outcomes in adult cancer survivors: A systematic review (Doctoral dissertation).

Schwartz, A. L., Meek, P. M., Nail, L. M., Fargo, J., Lundquist, M., Donofrio, M., ... \& Mateo, M. (2002). Measurement of fatigue: determining minimally important clinical differences. Journal of clinical epidemiology, 55(3), 239-244.

Shun, S. C., Lai, Y. H., \& Hsiao, F. H. (2009). Patient-related barriers to fatigue communication in cancer patients receiving active treatment. The Oncologist, 14(9), 936-943.

Strebkova, R., Petkova, M., \& Minev, M. (2017). Assessment of cancer related fatigue. Trakia Journal of Science, 15(3), 238-243.

Sun, V., Borneman, T., Koczywas, M., Cristea, M., Piper, B. F., Uman, G., \& Ferrell, B. (2012). Quality of life and barriers to symptom management in colon cancer. European Journal of Oncology Nursing, 16(3), 276-280.

Sweegers, M. G., Peeters, P. H. M., Courneya, K. S., Newton, R. U., Aaronson, N. K., Jacobsen, P. B., ... \& Stuiver, M. M. (2019). Moderators of Exercise Effects on 
Cancer-related Fatigue: A Meta-analysis of Individual Patient Data. Medicine and science in sports and exercise.

Tabrizi, F. M., \& Alizadeh, S. (2017). Cancer related fatigue in breast cancer survivors: in correlation to demographic factors. Maedica, 12(2), 106.

Tian, L., Yang, Y., Sui, W., Hu, Y., Li, H., Wang, F., ... \& Tao, M. (2017). Implementation of evidence into practice for cancer-related fatigue management of hospitalized adult patients using the PARIHS framework. PloS one, 12(10), e0187257.

Werdani, Y. D. W. (2018). Effect of Cancer Related Fatigue to the Level of Independence of Cancer Patients and Caregiver Stress Level. Folia Medica Indonesiana, 54(2), 108-112.

Yennurajalingam, S., Urbauer, D. L., Casper, K. L., Reyes-Gibby, C. C., Chacko, R., Poulter, V., \& Bruera, E. (2011). Impact of a palliative care consultation team on cancer-related symptoms in advanced cancer patients referred to an outpatient supportive care clinic. Journal of Pain and Symptom Management, 41(1), 49-56.

\section{فعالية تطبيق إرشادات تمريضية عن الآجهاد على المخرجات الصحية لمريض الآورام}

\section{الخـلاصـة}

يعد الإعياء المرتبط بالسرطان من أكثر المضاعفات حدوثا لدى مرضى السرطان حيث تُعاني نسبة كبيرة من مرضى

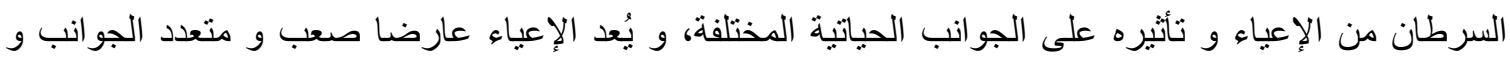
العوامل و المسبيات، تتضمن العوامل الحيوية و النفسية و السلوكية. تهدف هذه الدراسة الى تقييم تأثير تطبيق الأرشادات التمريضية للتقليل الإعياء لدى مرضى السرطان. وأجريت هذه الدراسة فى مركز الأورام بمستشفى

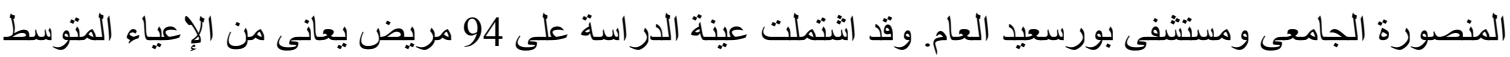

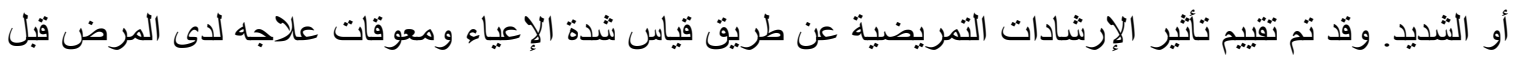
تطبيق الإرشادات وبعد شهر ثم بعد ثلاثة أشهر من تطبيق الإرشادات التمريضية. وقد أظهرت النتائج تحسن ملحوظ للإعباء لاى المرضى الخاضعين للار اسة واستمرار ذلك بعد ثلاث أثشهر من بدء التنخلات التمريضيه. الخلاصة:

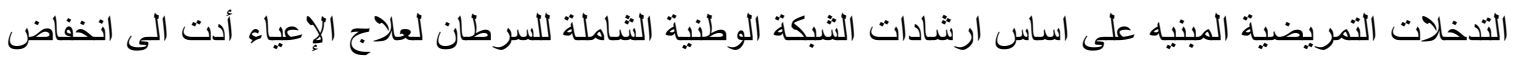


شدة الإعياء لاى المشاركين. وأوصت الدراسة بالتقييم اليومى للأعياء لدى مرضى السرطان و تقديم وسائل تثقيفية للمرضى عن الإعياء وطرق علاجه و أيضا تقليل المعوقات المرتبطة بعلاجه. الكلمات المرشدة : :- إرشادات تمريضية، الآجهاد، مخرجات صحية ، مريض الآورام 